\title{
Claudin-1 required for HCV virus entry has high potential for phosphorylation and O-glycosylation
}

\author{
Waqar Ahmad', Khadija Shabbiri², Bushra ljaz', Sultan Asad ${ }^{1}$, Muhammad T Sarwar ${ }^{1}$, Sana Gull', Humera Kausar ${ }^{1}$, \\ Kiran Fouzia ${ }^{2}$, Imran Shahid ${ }^{1}$ and Sajida Hassan ${ }^{1 *}$
}

\begin{abstract}
HCV is a leading cause of hepatocellular carcinoma and cirrhosis all over the world. Claudins belong to family of tight junction's proteins that are responsible for establishing barriers for controlling the flow of molecules around cells. For therapeutic strategies, regulation of viral entry into the host cells holds a lot of promise. During HCV infection claudin-1 is highly expressed in liver and believed to be associated with HCV virus entry after HCV binding with or without co-receptor CD81. The claudin-1 assembly with tight junctions is regulated by post translational modifications. During claudins assembly and disassembly with tight junctions, phosphorylation is required at C-terminal tail. In cellular proteins, interplay between phosphorylation and O- $\beta$-GlcNAc modification is believed to be functional switch, but it is very difficult to monitor these functional and vibrant changes in vivo. Netphos 2.0 and Disphos 1.3 programs were used for potential phosphorylation; NetPhosK 1.0 and KinasePhos for kinase prediction; and YinOYang 1.2 and OGPET to predict possible O-glycosylation sites. We also identified Yin Yang sites that may have potential for $O-\beta$-GICNAc and phosphorylation interplay at same Ser/Thr residues. We for the first time proposed that alternate phosphorylation and O- $\beta$-GlcNAc modification on Ser 192, Ser 205, Ser 206; and Thr 191 may provide an on/off switch to regulate assembly of claudin-1 at tight junctions. In addition these phosphorylation sites may be targeted by novel chemotherapeutic agents to prevent phosphorylation lead by HCV viral entry complex.
\end{abstract}

\section{Introduction}

$\mathrm{HCV}$, the deadly virus has infected almost $3 \%$ of the world population. Most of the infected patients develop chronic infection leading to end stage hepatocellular carcinoma. A better understanding of mechanism of infection and the potential host co-factors facilitating its replication is an urgent need of the hour for the release of disease burden and vaccine development [1-3].

In multicellular organisms, movement of ions, proteins and water is controlled by barriers known as tight junctions (TJs) formed by epithelial and endothelial cell monolayers [4]. While tight junctions require the coordinated activity of several different proteins, the specificity of tight junction's permeability is regulated by transmembrane proteins known as claudins [5]. Entry of $\mathrm{HCV}$ in to the hepatocytes is a complex process and involves interaction of $\mathrm{HCV}$ glycoproteins E1 and E2

\footnotetext{
* Correspondence: sajihassan2004@yahoo.com

'Applied and Functional Genomics Lab, Centre of Excellence in Molecular

Biology, University of the Punjab, Lahore-53700, Pakistan

Full list of author information is available at the end of the article
}

with host receptor CD81 and scavenger receptor class $\mathrm{B}$ member I (SR-BI). It is reported that these two receptors are not sufficient for its entry and later another receptor claudin-1 was discovered which play an important role in viral entry lately after viral binding to the CD81 [6,7]. Claudins are transmembrane proteins which play important role in tight junction formation and act as barrier in cellular permeability. Tight junctions are the combination of transmembrane and peripheral proteins tied with cytoskeleton. Several classes of claudin interact with other proteins to form tight junction and regulate permeability of TJs. It is also observed that the expression of claudin proteins found to be differentially regulated in several cancers. Claudin-1 expression was observed up-regulated in liver, stomach, thyroid, pancreas and cervix tumor formations [8-12]. Claudin-1 removal in mouse epidermis results in dramatic transepidermal water loss, inferring its indispensable role in creating and maintaining the epidermal barrier [13].

In biological systems, protein localization, activity, their interaction with other proteins and overall

\section{Biomed Central}


turnover is determined by post translational modifications (PTMs) [14]. Several PTMs like phosphorylation, glycosylation, acetylation and methylation are some well known examples. Phosphorylation in claudin protein family is well observed and believed to be modulating TJs permeability on both charged and uncharged ligands and molecules $[9,15]$. Several enzymes like protein kinase A (PKA), protein kinase C (PKC), protein phosphatase 2A (PP2A), MAPK etc are involved during claudin phosphorylation [16-18]. Phosphorylation has dual effect on TJs functionality i.e. phosphorylation on some claudins increased paracellular permeability or enhanced barrier function [19]. It is reported that claudin-1 phosphorylation enhances its barrier functions while dephosphorylation leads to detergent solubility and enhanced paracellular permeability [20].

$O$-glycosylation is also very important PTM of nuclear and cytoplasmic proteins. During $O$-glycosylation one molecule of $\mathrm{N}$-acetylglucosamine (O-GlcNAc) is introduced on Ser or Thr residue by enzyme OGT ( $O$ GlcNAc transferase). Addition of O- $\beta$-GlcNAc can inhibit phosphorylation on Ser or Thr residue. Interplay between O- $\beta$-GlcNAc modification and phosphorylation on the same amino acid residues has been observed in several nuclear and cytoplasmic proteins [21]. These PTMs are dynamic and result in temporary conformational changes and regulate many functions of the proteins. The interchange of these two modifications on the same or neighboring residue may modulate the specific function of the proteins either by enhancing or inhibiting the functional capacity. Residues where O- $\beta$-GlcNAc and phosphorylation compete for each other are known as Yin Yang sites [22]. These Yin Yang sites can be predicted and analyzed using various computer-assisted neural network-based programs, which can help us to determine proteins regulatory functions by accessing their modification potentials. The present work describe potential phosphorylation, $O$-glycosylation and their possible interplay sites which may influence claudin-1 interaction with TJs and their possible effects on $\mathrm{HCV}$ entry and future therapeutics.

\section{Materials and methods}

The FASTA sequence of human claudin-1 was retrieved from the SWISS-PROT sequence database [23] with entry name CLD1_human. The primary accession number for this sequence was O95832. Homology search was made using the BLAST at NCBI database with default parameters [24]. The search was made for all organisms' sequences. A total of 250 hits were retrieved for claudin-1 with highest bits score and zero expected values. Out of 70 retrieved sequences, seven were selected representing major mammalian or vertebrate groups. The accession numbers for eight selected sequences (Table 1) were O95832 (Human), Q6L708 (Bovine), D6RU0 (Sheep), C3VMK8 (Pig), O88551 (Mouse), P56745 (Rat), Q5ZMG2 (Chick) and Q5FW44 (Xentr). ClustalW [25] was used for multiple alignments of all the sequences of claudin-1 to get the conservation status.

The claudin-1 sequence used in this study was "MANAGLQLLGFILAFLGWIGAIVSTALPQWRIYSYAGDNI VTAQAMYEGLWMSCVSQSTGQIQCKVFDSLLNLS STLQATRALMVVGILLGVIAIFVATVGMKCMKCLED DEVQKMRMAVIGGAIFLLAGLAILVATAWYGNRIV QEFYDPMTPVNARYEFGQALFTGWAAASLCLLGG ALLCCSCPRKTTSYPTPRPYPKPAPSSGKDYV".

\section{Post-translational modifications prediction methods}

We used more than one bioinformatics tools to access the post-translational modification on claudin-1 to get best results.

Prediction of phosphorylation residues and related kinases Phosphorylation potential for human claudin-1 was predicted by using NetPhos 2.0 [26] and Disphos 1.3 server [27]. These are neural network-based programs that predict the potential phosphorylation sites for each Thr, Ser and Tyr residues. The minimum threshold value used to predict phosphorylation is 0.5 for NetPhos 2.0.

Kinase specific phosphorylation sites in human claudin-1 were predicted by NetPhosK 1.0 [28] and KinasePhos 2.0 server [29]. These servers predict the kinase specific acceptor substrates including Ser, Thr and Tyr.

For the evaluation of experimentally verified phosphorylation sites on human claudin-1, Phospho.ELM database was used [30]. This database contains a collection of experimentally confirmed Ser, Thr and Tyr residues in eukaryotic proteins.

Table 1 Different claudin-1 proteins used for multiple alignment

\begin{tabular}{cccccc}
\hline $\begin{array}{c}\text { Species } \\
\text { name }\end{array}$ & $\begin{array}{c}\text { Universal } \\
\text { name }\end{array}$ & $\begin{array}{c}\text { Accession } \\
\text { no. }\end{array}$ & Identity & Score & E-Value \\
\hline Homo sapiens & Human & O95832 & $100 \%$ & - & - \\
\hline Bos tauurus & Bovine & Q6L708 & $92.0 \%$ & 1,053 & $\begin{array}{c}1.0 \times 10- \\
113\end{array}$ \\
\hline Ovis aries & Sheep & D6R6U0 & $91.0 \%$ & 1,049 & $\begin{array}{c}1.0 \times 10- \\
112\end{array}$ \\
\hline $\begin{array}{c}\text { Sus scrofa } \\
\text { Pig }\end{array}$ & C3VMK8 & $92.0 \%$ & 1,018 & $\begin{array}{c}1.0 \times 10- \\
109\end{array}$ \\
\hline $\begin{array}{c}\text { Mus musculus } \\
\text { Mouse }\end{array}$ & O88551 & $90.0 \%$ & 1,025 & $\begin{array}{c}1.0 \times 10- \\
109\end{array}$ \\
\hline $\begin{array}{c}\text { Rattus } \\
\text { novergicus }\end{array}$ & Rat & P56745 & $91.0 \%$ & 1,030 & $\begin{array}{c}1.0 \times 10- \\
110\end{array}$ \\
\hline $\begin{array}{c}\text { Gallus gallus } \\
\text { Chick }\end{array}$ & Q5ZMG2 & $74.0 \%$ & 875 & $\begin{array}{c}3.0 \times 10- \\
92\end{array}$ \\
\hline $\begin{array}{l}\text { Xenopus } \\
\text { tropicalis }\end{array}$ & Xentr & Q5FW44 & $67.0 \%$ & 800 & $\begin{array}{c}1.0 \times 10- \\
83\end{array}$ \\
\hline
\end{tabular}


Prediction of o-glycosylated residues and Yin Yang sites $O$ - $\beta$-GlcNAc modification potential sites were predicted by YinOYang 1.2 [31-34] and OGPET [35]. YinOYang 1.2 program can predict the potential phosphorylation sites as well and hence predict the Yin Yang sites with highly uneven threshold that is adjusted in accordance with amino acid surface accessibility. The potential Yin Yang sites can also be predicted using this method.

\section{Protein structure analysis}

As there is no template model of claudin-1 available in protein data bank [36], we designed an ab-initio model by using software I-TASSER [37]. Data in sequence form was uploaded to the server. Model with high $\mathrm{C}$ score was selected as ab-initio model. To view and analyze 3D structure Jmol [38] and PYmol [39] programs were used. To assess, whether the predicted Ser and Thr residues have surface accessibility for post-translational modifications, NetSurfP was used [40].

\section{Neural networks-based prediction methods}

All the methods used for predicting post translational modifications like ANNs (artificial neural networks) or SVM (support vector machine) etc have been extensively used in biological sequence study and predicting the possible potentials for PTMs [41]. The methods developed using machine learning approach includes memorizing the neural networks with the sequence environment windows of phosphorylated/glycosylated and non-phosphorylated/non-glycosylated sites. The input data of phosphorylated/glycosylated and nonphosphorylated/non-glycosylated sites is presented to the neural networks in the form of binary codes of 21 digits. A threshold value in the form of bits is set for positive hit and zero for negative hits. The learning process and performance is checked with the data reserved for cross validation using statistical equations. During learning, the error is computed and weights given to each neuron are set to get the maximum correct predictions. It helps in reducing the error and hence decreasing the false positive and false negative prediction sites.

\section{Results}

Alignment of sequences for the determination of conserved status of Ser/Thr residues within claudin-1

Human claudin-1 was aligned with other species. Conserved and semi-conserved substituted Ser and Thr residues within each subtype were determined (Figure 1). It is clear from figure that Ser 34, 53, 58, 69, 185 and 192; and Thr $42,59,80,153$ and 191 are highly conserved in vertebrates. Meanwhile, Ser 24, 56, 75, 173, 205 and 206; and Thr 25, 76, 99, 167, 190 and 195 are conserved in mammals.

\section{Acquiring experimentally verified $\mathrm{S} / \mathrm{T} / \mathrm{Y}$ residues}

Data for experimentally confirmed $\mathrm{S} / \mathrm{T} / \mathrm{Y}$ residues was obtained from Phospho.ELM and UniprotKB http:// www.uniprot.org. Human claudin-1 has three phosphorylation sites Tyr 203, Ser 205 and Ser 206 by similarity with Mus musculus.

\section{Prediction of Phosphorylation Sites}

For the prediction of possible Ser and Thr residues for potential phosphorylation, NetPhos 2.0 server was used. A total of 7 sites showed high potential for phosphorylation. Amongst these 3 were Ser, 3 Thr and 1 was Tyr. All these 7 predicted sites were highly conserved in mammals (Figure 2A). Ser 58, Thr 99 and Thr 190 showed probable potential for phosphorylation. On the other hand DisPhos 1.3 predicts Thr 191, 195 and Ser 205, 206 for high and Ser 192 for probable phosphorylation potential.

\section{Prediction of Kinases involved in Phosphorylation}

A number of kinases may be implicated for phosphorylation of Ser and Thr residues. Almost each kinase predicted is involved in phosphorylation of two or more residues. The predicted kinases involved in phosphorylation of claudin-1 by NetPhos K, KinasePhos are shown in Table 2 .

\section{Prediction of O-linked glycosylation sites}

Prediction results for $O$-linked glycosylation sites showed that claudin- 1 has potential for $O-\beta$-GlcNAc modification (Figure $2 \mathrm{~B}$ ). YinOYang 1.2 predicted 4 potential sites for O- $\beta$-GlcNAc modification including Ser 192, 205 and 206; and Thr 191. All these sites were highly conserved in vertebrates. Ser 206 was replaced by Thr in chick. OGPET predicts Ser 56, 205, 206 and Thr 42, 59, 153, 167, 195 for high O-glycosylation potential.

\section{Identification of False-Negative Sites}

The Ser and Thr residues which were not predicted to be $O-\beta$-GlcNAc modified but showed very high potential for phosphorylation and were close to threshold value are known as false-negative sites (FN-sites). A list of Yin Yang and FN-Yin Yang residues is given in Table 3. Two residues Thr 153 and Thr 195 was predicted as FN-residue. Thr 153 was highly conserved in vertebrates while Thr 195 was conserved in mammals (Figure 1).

\section{Potential Yin Yang sites for claudin-1}

For the interplay of phosphorylation and $O-\beta$-GlcNAc modification, five possible Yin Yang sites were proposed (Figure 2C). These Yin Yang sites are proposed on the basis of conservation status of Ser/Thr residues in claudin-1. The Ser/Thr residues are also proposed for the possible interplay of phosphorylation and $O-\beta$-GlcNAc modification on the basis of their similarity with other species. These Ser/Thr residues which are predicted "by similarity" are not yet experimentally known in human but these are known in other species of vertebrates. 
Table 2 Predicted phosphorylation and O-glycosylation sites on Claudin-1 protein

\begin{tabular}{|c|c|c|c|c|c|c|c|c|}
\hline \multirow[t]{2}{*}{ Substrate } & \multirow[t]{2}{*}{ Position } & \multicolumn{2}{|c|}{ Phosphorylation prediction } & \multicolumn{2}{|c|}{ Kinase prediction } & \multicolumn{2}{|c|}{ O-glycosylation prediction } & \multirow{2}{*}{$\frac{\text { Surface accessibility }}{\text { NetSurfP }}$} \\
\hline & & Netphos & Disphos & NetphosK & Kinasephos & YinOYang & OGPET & \\
\hline Ser & 24 & $\mathrm{~N}$ & $\mathrm{~N}$ & - & - & $\mathrm{N}$ & HP & B \\
\hline Thr & 25 & $\mathrm{~N}$ & $\mathrm{~N}$ & CDC2 & - & $\mathrm{N}$ & $L P$ & B \\
\hline Ser & 34 & $\mathrm{~N}$ & $\mathrm{~N}$ & PKA & - & $\mathrm{N}$ & $L P$ & B \\
\hline Thr & 42 & $\mathrm{~N}$ & $\mathrm{~N}$ & - & MDD & $\mathrm{N}$ & $\mathrm{VHP}$ & $B$ \\
\hline Ser & 53 & $\mathrm{~N}$ & $\mathrm{~N}$ & - & - & $\mathrm{N}$ & $L P$ & B \\
\hline Ser & 56 & $\mathrm{~N}$ & $\mathrm{~N}$ & DNAPK & PKG & $\mathrm{N}$ & VHP & B \\
\hline Ser & 58 & P & $\mathrm{N}$ & PKC & ATM, IKK & $\mathrm{N}$ & $\mathrm{HP}$ & E \\
\hline Thr & 59 & $\mathrm{~N}$ & $\mathrm{~N}$ & - & PKG & $\mathrm{N}$ & $\mathrm{VHP}$ & $E$ \\
\hline Ser & 69 & $\mathrm{~N}$ & $\mathrm{~N}$ & PKA & - & $\mathrm{N}$ & $L P$ & B \\
\hline Ser & 74 & $\mathrm{~N}$ & $\mathrm{~N}$ & - & $\mathrm{CKI}$ & $\mathrm{N}$ & $L P$ & $E$ \\
\hline Ser & 75 & $\mathrm{~N}$ & $\mathrm{~N}$ & - & CKI & $\mathrm{N}$ & $\mathrm{HP}$ & $E$ \\
\hline Thr & 76 & $\mathrm{~N}$ & $\mathrm{~N}$ & - & CDK & $\mathrm{N}$ & $L P$ & $B$ \\
\hline Thr & 80 & $\mathrm{~N}$ & $\mathrm{~N}$ & - & - & $N$ & $L P$ & B \\
\hline Thr & 99 & $P$ & $\mathrm{~N}$ & PKC & - & $\mathrm{N}$ & $L P$ & B \\
\hline Thr & 137 & $\mathrm{~N}$ & $\mathrm{~N}$ & - & - & $\mathrm{N}$ & $L P$ & B \\
\hline Thr & 153 & Y & $\mathrm{N}$ & MAPK, GSK3 & CDC2, MAPK & $\mathrm{N}$ & $\mathrm{VHP}$ & B \\
\hline Thr & 167 & $\mathrm{~N}$ & $\mathrm{~N}$ & PKC, CDC2 & - & $\mathrm{N}$ & $\mathrm{VHP}$ & B \\
\hline Ser & 173 & $\mathrm{~N}$ & $\mathrm{~N}$ & PKA & - & $\mathrm{N}$ & $L P$ & B \\
\hline Ser & 185 & $\mathrm{~N}$ & $\mathrm{~N}$ & $\mathrm{CDC2}$ & - & $\mathrm{N}$ & $L P$ & B \\
\hline Thr & 190 & $P$ & $\mathrm{~N}$ & PKA & PKA & $\mathrm{N}$ & $\mathrm{HP}$ & $E$ \\
\hline Thr & 191 & Y & Y & PKG & PKC, PKA & $Y$ & $L P$ & $E$ \\
\hline Ser & 192 & Y & $\mathrm{P}$ & - & PKA, IKK, PKB & Y & $L P$ & E \\
\hline Thr & 195 & Y & Y & MAPK, CDC5 & PKC, MAPK, CDK & $\mathrm{N}$ & VHP & $E$ \\
\hline Ser & 205 & Y & Y & PKG & $\mathrm{CDC2}$ & Y & VHP & E \\
\hline Ser & 206 & Y & Y & PKC & - & Y & VHP & $E$ \\
\hline
\end{tabular}

$\mathrm{Y}=$ yes (threshold $>0.5$ ), $\mathrm{P}=$ probable (threshold $>0.1 \sim 0.5$ ), $\mathrm{N}=$ No (threshold $<0.1$ ), $\mathrm{B}=$ Buried surface, $\mathrm{E}=$ Exposed surface, $\mathrm{VHP}=$ very high potential (threshold $\geq 1.0$ ), $\mathrm{HP}=$ high potential (threshold $>0.8<1.0$ ), $\mathrm{LP}=$ low potential (threshold $<0.8$ )

\section{Discussion}

Among vertebrates claudin-1 has highly conserved globular domain while, less conserved $\mathrm{N}$ - and C-terminals. Claudin-1 also showed highly conserved status among mammals (Figure 1). The claudin tails especially $\mathrm{C}$-terminal is believed to be post-translationally modified $[9,16,42]$. The $\mathrm{C}$ and $\mathrm{N}$ - terminals of claudin associate with a number of proteins like multi-PDZ protein MUPP1, Pals1 and Zonula occludens proteins 1, 2 and 3 [43]. Evans et al. (2007) found that claudin1 was necessary for HCV entry after its binding with CD81 receptors. Recent findings showed that claudin-1 can enable cell to cell transfer of $\mathrm{HCV}$ [7] and the C- terminal of claudin is related to protein stability, altering protein turnover and therefore the paracellular permeability [44].

It is interesting to note that the post translational modifications regulate the TJ proteins functions. However little data is available. Phosphorylation of claudin is reported to be linked with permeability modulation of TJs $[9,44]$. Claudin-4 is phosphorylated on Ser-194, Thr189 , claudin-3 at Thr-192, claudin-16 at Ser-217, claudin-5 at Thr-205 and Thr-207 [45-54]. In most claudins, phosphorylation at C-terminal disrupts the functions of TJs in many cancers. It is already reported that in HCV, claudin-1 expression was high as compared to other

Table 3 Proposed Ser/Thr residues for the interplay of phosphorylation and 0 - $\beta$-GlcNAc modification in human claudin-1

\begin{tabular}{|c|c|c|c|c|}
\hline \multicolumn{2}{|c|}{ SUBSTRATE } & \multirow{2}{*}{$\frac{\text { Proposed Yin Yang sites }}{192,205,206}$} & \multirow{2}{*}{ Proposed Fn-Yin Yang sites } & \multirow{2}{*}{ Yin Yang sites by similarity } \\
\hline Cluadin-1 & SER & & & \\
\hline & THR & 191 & 195 & - \\
\hline
\end{tabular}




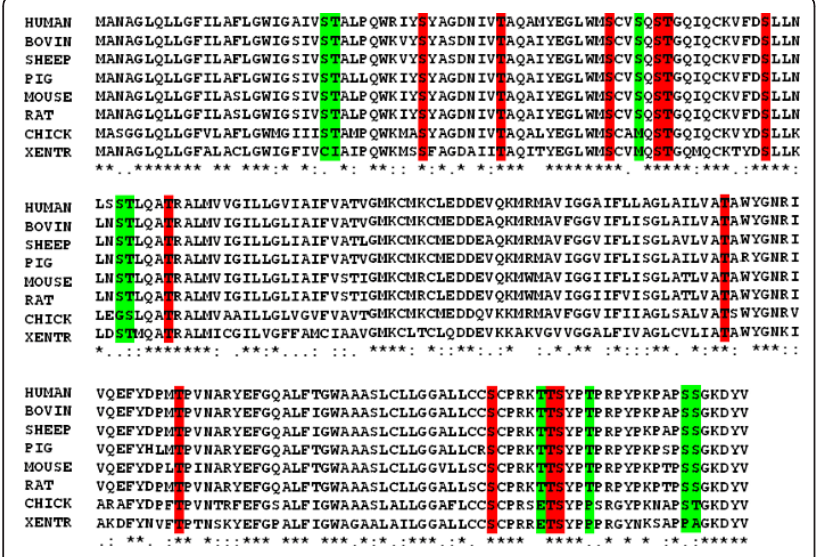

Figure 1 Multiple alignments of seven vertebrates sequences (Human, Bovine, Sheep, Pig, Mouse, Rat, Chick and Xentr).

These sequences were ordered as in aligned results from ClustalW. The consensus sequence is marked by an asterisk, conserved substitution by a double dot, and semiconserved substitution by a single dot.

subtypes [41-43]. In mouse claudin-1, it was observed that phosphorylation on Ser and Thr residues involved in promotion of tight-junctions functions. Mouse claudin-1 is found to be phosphorylated at Ser-205, 206; and Thr-203 [46]. Thr-203 is not present in human claudin1 and replaced with alanine residue (Figure 1). It was also observed that claudin-1 has been phosphorylated on various Ser and Thr residues in Caco- 2 cell line by PKC- $\theta$ [47]. Moreover, Ser-205 and 206 are highly conserved residues in mammals and thought to be phosphorylated in other species. To predict phosphorylation sites on human claudin-1 protein, we used two tools; NetPhos and DisPhos. The predicted phosphorylation residues are given in Table 2. It is obvious from Figure 2 that Ser192, 205 and 206; while Thr153, 191 and 195 showed high potential, while Thr-190 showed probable potential for phosphorylation. Most of the high potential sites were in C-terminal. These residues were conserved in vertebrates except Thr-195. We can speculate that these residues may be possible potential phosphorylated sites in human claudin-1.

Phosphorylation of claudins by various kinases and their impact on TJs regulation is well documented. In our study we predicted many kinases that may be involved in claudin-1 phosphorylation on Ser and Thr residues irrespective of their potential to be phosphorylated. We observed that kinases such as MAPK, CDC2, PKA, PKC, PKB, and CDK were involved in human claudin-1 phosphorylation. PKC activity was observed for claudin-1, while the other claudins are phosphorylated by PKA, PKC, MPAK and EphA2. It is also reported that suppression of kinase activity disrupts $\mathrm{TJ}$ formation $[9,19,44-55]$. These reports indicate that

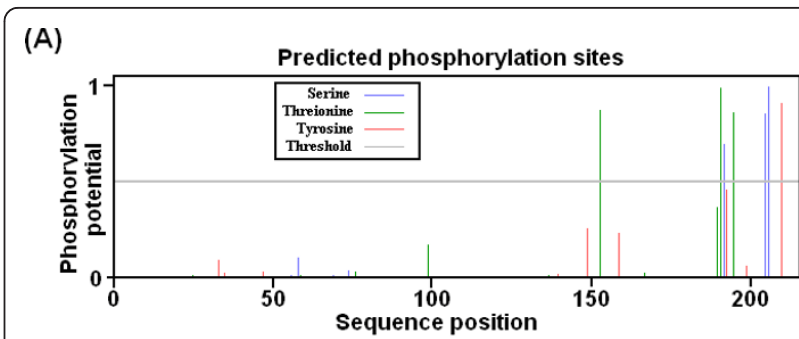

(B)

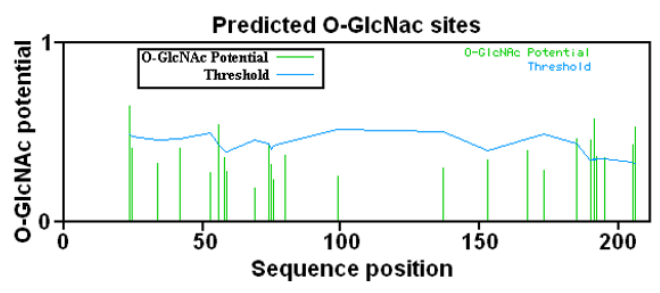

(C)

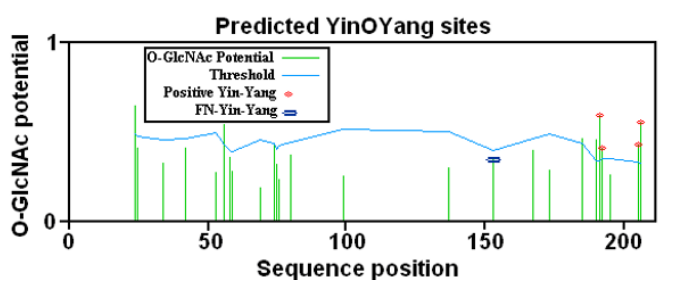

Figure 2 Graphic representation of the potential Ser, Thr, and Tyr residues for phosphorylation and O-glycosylation modification for human claudin-1. A) Predicted potential sites for phosphate modification on Ser and Thr residues. The light gray horizontal line indicates the threshold for modification potential. The blue, green and red vertical lines showed the potential phosphorylated Ser, Thr and Tyr residues, respectively. B) Predicted potential sites for O-glycosylation modification of Ser and Thr. O- $\beta$ GlcNAc modification potential of Ser/Thr residues is shown by green vertical line, while the light blue wavy line indicates the threshold for modification potential. C) The Yin Yang sites that were positively predicted are shown with red asterisk at the top, while the NP-Yin Yang site are shown with purple asterisk on the top of vertical lines. The green vertical lines show the O- $\beta$-GIcNAc potential of Ser/Thr residue and the light blue horizontal wavy line indicates the threshold for modification potential.

claudin phosphorylation on C-terminal is involved in TJs formation and their performance. It was also interesting to note that claudin phosphorylation is associated with proper barrier function, while dephosphorylation negatively regulates the TJs $[48,49]$.

$O-\beta$-GlcNAc modification can occur on these Ser and Thr residues where kinases are involved in phosphorylation as it is well known that kinases and OGT can compete for same site modification [32-34,56]. It is well documented that phosphorylation and O- $\beta$-GlcNAc modification is also a regulatory adaptation, and changes during glycosylation are transient for few hours. This shows a possibility for interplay between phosphorylation and OGT on these residues. It functions by blocking Ser/Thr residues phosphorylation and can lead to 
changes in protein-protein interactions, singling and protein complex arrangements. This competitive interplay is known as Yin Yang hypothesis [57-61]. Many cytoplasmic proteins undergo O-glycosylation [62]. Our prediction results showed that human claudin-1 has high potential for $O$-linked glycosylation (Figure 3, Table 2). YinOYang 1.2 server detected four, while OGPET eight Ser and Thr residues with high potential for $\mathrm{O}$-glycosylation. It is clear from results that most of the residues belong to $\mathrm{C}$-terminal of claudin- 1 . YinOYang 1.2 predicts high potential for glycosylation and their chances to become possible Yin Yang sites on Ser 192, 205 and 206; and Thr 191 (Figure 2B). Although Thr 153 and 195 has high potential for phosphorylation, these residues were not predicted to act as possible Yin Yang interplay. However, OGPET 1.0 predicts high potential for O-glycosylation on Ser 56 and, Thr 42, 59, 153, 167 and 195 based on their sequence motifs. These residues are conserved in mammals and may act as possible FN-Yin Yang sites based on their phosphorylation potential [32-34].

To predict possible Yin Yang sites, we drew the 3D structure of claudin-1 (Figure 3). We also assessed the possible surface accessibility of claudin-1 for these post translational modifications (Table 2). We found that Ser 56 and Thr 42, 153 and 167 were predicted as "Buried"

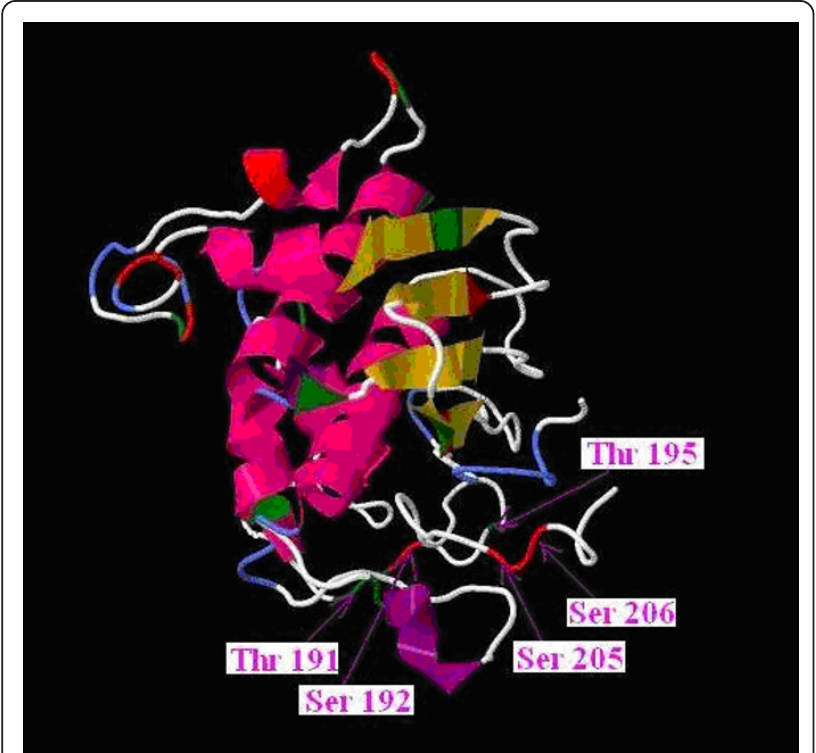

Figure 3 A homology model of human claudin-1 utilizing automated protein modeling option was retrieved through ITASSER server. Through this option five models were received from the server utilizing five different templates namely: model 1-5. Among the five, one that covered all amino acids with alpha helix structure and beta pleated sheet, and high C-value was selected. This model showed that predicted Yin Yang sites have high surface accessibility for the phosphorylation and O-glycosylation interplay. The Ser and Thr residues are denoted by red and green colors. i.e. not accessible for these types of modifications [40], while Ser 192, 205 and 206, and Thr 191 and 195 as "exposed" surfaces. This information depicts that Ser and Thr residues present at C-terminal have high access to these types of modifications.

We, therefore propose that phosphorylation and O- $\beta$ GlcNAc modifications on cytoplasmic C-terminal Ser and Thr residues of claudin-1 control the TJs functionality. Blocking the phosphorylation by O- $\beta$-GlcNAc modification on Ser 192, 205, 206, and Thr 191 and 195 can disrupt the binding of claudin-1 with other cytoplasmic proteins and reduce its cooperation during $\mathrm{HCV}$ viral entry. Furthermore, these potential phosphorylation sites of claudin-1 do present themselves as attractive candidates for novel chemotherapeutic agents, resulting in the halting HCV entry in the host cells.

\section{Abbreviations}

HCV: Hepatitis C virus; CD81: cluster of differentiation 81; TJ: Tight junctions.

\section{Author details}

${ }^{1}$ Applied and Functional Genomics Lab, Centre of Excellence in Molecular Biology, University of the Punjab, Lahore-53700, Pakistan. ${ }^{2}$ Department of Chemistry, GC University Lahore, Pakistan.

\section{Authors' contributions}

WA and KS contributed equally to this study. WA, KS and SH designed the study. SA, SG, HK, KF, MTS and IS analyzed the data and wrote paper. All work was performed under supervision of $\mathrm{SH}$. All authors read and approve the final manuscript.

\section{Authors' information}

Bushra ljaz (M Phil Molecular Biology), Wagar Ahmad (M Phil Chemistry) and Gull S (MSc Biochemistry) are Research Officer; Shabbiri K is lecturer while Fouzia K is BS (Hons) student at GC University, Lahore. Kausar H, Sawar MT and Shahid I are Phd scholars. Asad S is MPhil scholar, while Sajida Hassan (PhD Molecular Biology) is Principal Investigator at CEMB, University of the Punjab, Lahore

\section{Competing interests}

The authors declare that they have no competing interests.

Received: 5 March 2011 Accepted: 15 May 2011 Published: 15 May 2011

\section{References}

1. Giannini C, Brechot C: Hepatitis C virus biology. J Virol 2003, 10:S27-S38.

2. Alter MJ: Epidemiology of hepatitis C. Hepatology 1997, 26:62S-65S.

3. EL-Serag HB: Hepatocellular carcinoma and hepatitis $C$ in the United States. Hepatology 2002, 36:S74-S83.

4. Schneeberger EE, Lynch RD: The tight junction: A multifunctional complex. Am J Physiol Cell Physiol 2004, 286:1213-1228.

5. Angelow S, Ahlstrom R, Yu AS: Biology of Claudins. Am J Physiol Renal Physiol 2008, 295:867-876.

6. Helle F, Dubuisson J: Hepatitis C virus entry into host cells. Cell Mol Life Sci 2008, 65:100-112.

7. Evans MJ, von Hahn T, Tscherne DM, Syder AJ, Panis M, Wölk B, Hatziioannou T, McKeating JA, Bieniasz PD, Rice CM: Claudin-1 is a hepatitis $C$ virus co-receptor required for a late step in entry. Nature 2007, 446:801-8055.

8. Van Itallie CM, Anderson JM: Claudins and epithelial paracellular transport. Annu Rev Physiol 2006, 68:403-429.

9. Oliveira SS, Oliveira IM, De Souza W, Morgado-Diaz JA: Claudins upregulation in human colorectal cancer. FEBS Lett 2005, 579:6179-6185.

10. lacobuzio-Donahue CA, Maitra A, Shen-Ong GL, van Heek T, Ashfaq R, Meyer R, Walter K, Berg K, Hollingsworth MA, Cameron JL, Yeo CJ, Kern SE, 
Goggins M, Hruban RH: Discovery of novel tumor markers of pancreatic cancer using global gene expression technology. Am J Pathol 2002, 160:1239-1249.

11. Fluge $O$, Bruland O, Akslen LA, Lillehaug JR, Varhaug JE: Gene expression in poorly differentiated papillary thyroid carcinomas. Thyroid 2006, 16:161-175.

12. Resnick MB, Gavilanez M, Newton E, Konkin T, Bhattacharya B, Britt DE, Sabo $E$, Moss SF: Claudin expression in gastric adenocarcinomas: a tissue microarray study with prognostic correlation. Hum Pathol 2005, 36:886-892.

13. Furuse $M$, Hata M, Furuse $K$, Yoshida $Y$, Haratake A, Sugitani $Y$, Noda T, Kubo A, Tsukita S: Claudin- based tight junctions are crucial for the mammalian epidermal barrier: a lesson from claudin-1-deficient mice. $J$ Cell Biol 2002, 156:1099-1111.

14. Mann M, Jensen ON: Proteomic analysis of post-translational modifications. Nat Biotechnol 2003, 21:255-261.

15. Gonzalez-Mariscal L, Garay E, Quiros M: Regulation of claudins by posttranslational modifications and cell signaling cascades. Current Topics in Membranes 2010, 65:113-150.

16. D'Souza T, Agarwal RPJ: Phosphorylation of Claudin-3 at Threonine 192 by cAMP-dependent Protein Kinase Regulates Tight Junction Barrier Function in Ovarian Cancer Cells. J Biol Chem 2005, 280:26233-26240.

17. D'Souzaa T, Indigb FE, Morina PJ: Phosphorylation of claudin-4 by pkce regulates tight junction barrier function in ovarian cancer Cells. Exp Cell Res 2007, 313:3364-3375.

18. French AD, Fiori JL, Camilli TC, Leotlela PD, O'Connell MP, Frank BP, Subaran S, Indig FE, Taub DD, Weeraratna AT: PKC and PKA phosphorylation affect the subcellular localization of claudin-1 in melanoma cells. Int J Med Sci 2009, 6:93-101.

19. Soma T, Chiba H, Kato-Mori Y, Wada T, Yamashita T, Kojima T, Sawada N: Thr (207) of claudin-5 is involved in size-selective loosening of the endothelial barrier by cyclic AMP. Exp Cell Res 2004, 300:202-212.

20. Nunbhakdi-Craig V, Machleidt T, Ogris E, Bellotto D, White CL, Sontag E: Protein phosphatase $2 \mathrm{~A}$ associates with and regulates atypical PKC and the epithelia tight junction complex. J Cell Biol 2002, 158:967-978.

21. Kamemura K, Hayes BK, Comer Fl, Hart GW: Dynamic interplay between Oglycosylation and O-phosphorylation of nucleocytoplasmic proteins: alternative glycosylation/phosphorylation of THR-58, a known mutational hot spot of c-Myc in lymphomas, is regulated by mitogens. J Biol Chem 2002, 277:19229-19235.

22. Zachara NE, Hart GW: The emerging significance of $0-\beta-G l c N A c$ in cellular regulation. Chem Rev 2002, 102:431-438.

23. Boeckmann B, Bairoch A, Apweiler R, Blatter MC, Estreicher A, Gasteiger E, Martin MJ, Michoud K, O'Donovan C, Phan I, Pilbout S, Schneider M: The SWISS-PROT protein knowledgebase and its supplement TrEMBL in 2003. Nucleic Acids Res 2003, 31:365-370.

24. AltschuL SF, Madden TL, Schaffer AA, Zhang J, Zhang Z, Miller W, Lipman DJ: Gapped BLAST and PSI-BLAST: a new generation of protein database search programs. Nucleic Acids Res 1997, 25:3389-3402.

25. Thompson JD, Higgins DJ, Gibson TJ: CLUSTAL W: improving the sensitivity of progressive multiple sequence alignment through sequence weighting, position-specific gap penalties and weight matrix choice. Nucleic Acids Res 1994, 22:4673-46780[http://www.ebi.ac.uk/Tools/ msa/clustalw2/].

26. Blom N, Gammeltoft S, Brunak S: Sequence- and structure-based prediction of eukaryotic protein phosphorylation sites. J Mol Biol 1999, 294:1351-1362[http://www.cbs.dtu.dk/services/NetPhos/].

27. lakoucheva LM, Radivojac P, Brown CJ, O'Connor TR, Sikes JG, Obradovic Z, Dunker AK: Intrinsic disorder and protein phosphorylation. Nucleic Acids Res 2004, 32:1037-1049[http://www.ist.temple.edu/disphos/].

28. Blom N, Sicheritz-Ponten T, Gupta R, Gammeltoft S, Brunk S: Prediction of post-translational glycosylation and phosphorylation of proteins from the amino acid sequence. Proteomics 2004, 4:1633-1649[http://cbs.dtu.dk/ services/NetPhosK].

29. Huang HD, Lee TY, Tseng SW, Horng JT: KinasePhos: a web tool for identifying protein kinase-specific phosphorylation sites. Nucleic Acids Res 2005, 33:226-229[http://kinasephos.mbc.nctu.edu.tw/case2.html].

30. Diella F, Cameron S, Gemund C, Linding R, Via A, Kuster B, SicheritzPonten T, Blom N, Gibson TJ: Phospho.ELM: a database of experimentally verified phosphorylation sites in eukaryotic proteins. BMC Bioinformatics 2004, 22:79[http://phospho.elm.eu.org].
31. Gupta R, Brunak S: Prediction of glycosylation across the human proteome and the correlation to protein function. Pac Sym Biocomput 2002, 7:310-322[http://www.cbs.dtu.dk/services/YinOYang/].

32. Kaleem A, Hoessli DC, Haq IU, Walker-Nasir E, Butt A, Iqbal Z, Zamani Z, Shakoori AR, Nasir-ud-Din : CREB in long-term potentiation in hippocampus: role of post-translational modifications-studies In silico. $J$ Cell Biochem 2011, 112:138-146.

33. Ahmad I, Khan TS, Hoessli DC, Walker-Nasir E, Kaleem A, Shakoori AR, Nasirud-Din : In silico modulation of HMGN-1 binding to histones and gene expression by interplay of phosphorylation and $0-\beta-G I c N A C$ modification. Protein Pept Lett 2008, 15:193-199.

34. Kaleem A, Hoessli DC, Ahmad I, Walker-Nasir E, Nasim A, Shakoori AR, Nasirud-Din : Immediate-early gene regulation by interplay between different post-translational modifications on human histone H3. J Cell Biochem 2008, 103:835-851

35. Torres R, Almeida IC: O-glycosylation Prediction Electronic Tool (OGPET): a new algorithm for prediction of O-glycosylation sites. FASEB $J$ 2006, 20:1362[http://ogpet.utep.edu/OGPET/].

36. Pettersen EF, Goddard TD, Huang CC, Couch GS, Greenblatt DM, Meng EC, Ferrin TE: UCSF Chimera-a visualization system for exploratory research and analysis. J Comput Chem 2004, 25:1605-1612[http://zhanglab.ccmb. med.umich.edu/l-TASSER/].

37. Zhang Y: I-TASSER server for protein 3D structure prediction. BMC Bioinformatics 2008, 9:40.

38. Durme JV, Horn F, Costagliola S, Vriend G, Vassart G: GRIS: Glycoproteinhormone Receptor Information System. Molecular Endocrinology 2006, 20:2247-2255[http://jmol.sourceforge.net/].

39. The PyMOL Molecular Graphics System. Schrödinger, LLC; $[$ http://www. pymol.org/citing], Version 1.3, http://www.pymol.org/export.

40. Petersen B, Petersen TN, Andersen P, Nielsen M, Lundegaard C: A generic method for assignment of reliability scores applied to solvent accessibility predictions. BMC Structural Biology 2009, 9:5[http://www.cbs. dtu.dk/services/NetSurfP/].

41. Baldi $P$, Brunak S: Bioinformatics: The machine learning Approach. MIT Press. Cambridge, MA; 22002.

42. Lal-Nag M, Morin PJ: The claudins. Genome Biol 2009, 10:235.

43. Bauer HC, Traweger A, Zweimueller-Mayer J, Lehner C, Tempfer H, Krizbai I, Wilhelm I, Bauer H: New aspects of the molecular constituents of tissue barriers. J Neural Transm 2011, 118:7-21.

44. Van Itallie CM, Colegio OR, Anderson JM: The cytoplasmic tails of claudins can influence tight junction barrier properties through effects on protein stability. J Membr Biol 2004, 199:29-38.

45. Avila-Flores A, Rendon-Huerta E, Moreno J, Islas S, Betanzos A, RoblesFlores M, Gonzalez-Mariscal L: Tight-junction protein zonula occludens 2 is a target of phosphorylation by protein kinase C. Biochem J 2001, 360:295-304

46. Fujibe $M$, Chiba H, Kojima $T$, Soma $T$, Wada T, Yamashita T, Sawada N: Thr203 of claudin-1, a putative phosphorylation site for MAP kinase, is required to promote the barrier function of tight junctions. Exp Cell Res 2004, 295:36-47.

47. Banan A, Zhang $L$, Shaikh M, Fields JZ, Choudhary S, Forsyth CB, Farhadi A, Keshavarzian $A$ : theta Isoform of protein kinase $C$ alters barrier function in intestinal epithelium through modulation of distinct claudin isotypes: a novel mechanism for regulation of permeability. J Pharmacol Exp Ther 2005, 313:962-982.

48. Deissler HL, Deissler $H$, Lang GE: Inhibition of protein kinase $C$ is not sufficient to prevent or reverse effects of VEGF165 on claudin-1 and permeability in microvascular retinal endothelial cells. Invest Ophthalmol Vis Sci 2010, 51:535-42

49. Ishizaki T, Chiba H, Kojima T, Fujibe M, Soma T, Miyajima H, Nagasawa K, Wada I, Sawada N: Cyclic AMP induces phosphorylation of claudin-5 immunoprecipitates and expression of claudin-5 gene in blood-brainbarrier endothelial cells via protein kinase A-dependent and -independent pathways. Exp Cell Res 2003, 290:275-288.

50. Soma T, Chiba H, Kato-Mori Y, Wada T, Yamashita T, Kojima T, Sawada N: Thr (207) of claudin-5 is involved in size-selective loosening of the endothelial barrier by cyclic AMP. Exp Cell Res 2004, 300:202-212.

51. Yamauchi K, Rai T, Kobayashi K, Sohara E, Suzuki T, Itoh T, Suda S, Hayama A, Sasaki S, Uchida S: Disease-causing mutant WNK4 increases paracellular chloride permeability and phosphorylates claudins. Proc Natl Acad Sci USA 2004, 101:4690-4694. 
52. Nunbhakdi-Craig V, Machleidt T, Ogris E, Bellotto D, White CL, Sontag E: Protein phosphatase 2A associates with and regulates atypical PKC and the epithelial tight junction complex. J Cell Biol 2002, 158:967-978.

53. Tanaka M, Kamata R, Sakai R: EphA2 phosphorylates the cytoplasmic tail of Claudin-4 and mediates paracellular permeability. J Biol Chem 2005, 280:42375-42382.

54. Stamatovic SM, Dimitrijevic OB, Keep RF, Andjelkovic AV: Protein kinase Calpha-RhoA cross-talk in CCL2-induced alterations in brain endothelial permeability. J Biol Chem 2006, 281:8379-8388.

55. Ikari A, Matsumoto S, Harada H, Takagi K, Hayashi H, Suzuki Y, Degawa M, Miwa M: Phosphorylation of paracellin-1 at Ser217 by protein kinase $A$ is essential for localization in tight junctions. J Cell Sci 2006, 119:1781-1789.

56. Haltiwanger RS, Busby S, Grove K, Li S, Mason D, Medina L, Moloney D, Philipsberg G, Scartozzi R: O-glycosylation of nuclear and cytoplasmic proteins: regulation analogous to phosphorylation. J Biochem Biophys Res Commun 1997, 231:237-242.

57. Kearse KP, Hart GW: Lymphocyte activation induces rapid changes in nuclear and cytoplasmic glycoproteins. Proc Natl Acad Sci 1991, 88:1701-1705.

58. Kelly WG, Dahmus ME, Hart GW: RNA polymerase II is a glycoprotein modification of the $\mathrm{COOH}$-terminal domain by O-GIcNAc. J Biol Chem 1993, 268:10416-10426.

59. Cheng X, Hart GW: Alternative O-glycosylation/Ophosphorylation of serine-16 in murine estrogen receptor beta: post-translational regulation of turnover and transactivation activity. J Biol Chem 2000, 276:10570-10575.

60. Chou CF, Smith AJ, Omary MB: Characterization and dynamics of O-linked glycosylation of human cytokeratin 8 and 18. J Biol Chem 1992, 267:3901-3906.

61. O'Donnell N: Intracellular glycosylation and development. Biochim Biophys Acta 2002, 1573:336-345.

62. Comer Fl, Hart GW: O-Glycosylation of nuclear and cytosolic proteins. Dynamic interplay between O-GICNAc and O-phosphate. I Biol Chem 2000, 275(38):29179-29182.

doi:10.1186/1743-422X-8-229

Cite this article as: Ahmad et al.: Claudin-1 required for HCV virus entry has high potential for phosphorylation and O-glycosylation. Virology Journal 2011 8:229.

\section{Submit your next manuscript to BioMed Central and take full advantage of:}

- Convenient online submission

- Thorough peer review

- No space constraints or color figure charges

- Immediate publication on acceptance

- Inclusion in PubMed, CAS, Scopus and Google Scholar

- Research which is freely available for redistribution

Submit your manuscript at www.biomedcentral.com/submit 